\title{
Comparative Study of Positional Accuracies Using Three GPS Receivers
}

\author{
"NNAMANI, OJ; IJAWARE, VA \\ ${ }^{I}$ Department of Surveying and Geoinformatics, Federal University of Technology, Akure, Ondo State, Nigeria. \\ *Corresponding Author Email: john.nnamani@gmail.com
}

\begin{abstract}
The emergence of the Global Positioning System (GPS) receiver over the years has afforded the avenue to acquire data from various geospatial locations. This paper analyses and compares the accuracy of point positions collected using three Global Positioning System (GPS) receivers - South H66/H88, Sokkia radian IS, and ProMark 3. A field study was conducted on 5 control points within the Federal University of Technology Akure (FUTA) Campus. The One-way ANOVA test performed for the coordinates obtained from the three GPS receivers at an alpha level of 0.05 using SPSS version 16 reveals no statistically significant difference between the coordinates. Analysis of the result shows that South GPS, Sokkia GPS, and ProMark GPS receivers had horizontal misclosure values of $0.1337,0.1625$ and 0.2425 respectively, making South GPS best in obtaining accurate information on horizontal positions. For the vertical position, misclosure values of $0.0902,0.2336$, and 0.2771 respectively were obtained for the Three GPS receivers, thereby revealing that Sokkia GPS performed optimally in obtaining heights above the ellipsoid. However, as a combination of horizontal and vertical positions (3-Dimension), Sokkia GPS performed best while ProMark GPS performed averagely and South GPS performed least. This study shows that any of the three GPS receivers can provide reasonable accurate geographic data. However, a definite conclusion remains that the selection of an optimal GPS receiver in this study for any project will largely depend upon the user's needs and project requirements as the significant variation observed in the height coordinates should be further investigated.
\end{abstract}

\section{DOI:https://dx.doi.org/10.4314/jasem.v24i3.7}

Copyright: Copyright $\left({ }^{\circ} 2020\right.$ Nnamani and Ijaware. This is an open access article distributed under the Creative Commons Attribution License (CCL), which permits unrestricted use, distribution, and reproduction in any medium, provided the original work is properly cited.

Dates: Received: 16 November 2019; Revised: 11 January 2020; Accepted: 22 February 2020

Keywords: GPS Receivers, Accuracy, Position Determination, GPS Coordinates

GPS receivers have become widely used over recent years to improve efficiency and accuracy with applications, ranging from hunting to surveying, benefiting immensely from these devices. When using these receivers to collect data, accuracy is very important. Accuracies required generally depend on the needed deliverable output. Several applications such as navigation on the sea, oceanographic research, velocity and position in small scale geophysical exploration require low accuracy; applications such as hydrography, calibration of transponder system, precise navigation and seismic survey, etc; are categorized as medium accuracy requirements; and applications which require high accuracy include precise hydrographic surveying, marine engineering, geodynamics, precise height control, and other Engineering construction projects (Sjoberg, 2012). Shannon et al., (2002) noted that as the influx of GPS receivers into the field of surveying continues to grow, there has been much debate over the accuracy and application of the many GPS receivers available. With the advent of the latest GPS receivers, there has been improved accuracy of positional information as several factors such as satellite availability, multipath, clock errors, etc., degrade the required accuracy provided by the various GPS receivers.

A field study of various GPS receivers for data collection will help to understand the differences in accuracy obtainable from these receivers and their possible areas of application. The need to evaluate the accuracy of GPS receiver is also necessary to enlightenment potential users on the differences in horizontal and vertical positional accuracy obtainable from various GPS receiver types. It is with this in view that this paper aims to analyze and compare the position of points collected using different GPS receivers. Specific objectives include: to conduct a field study of survey points; analyze and compare results obtained using appropriate statistics.

In the past years, studies have been carried out on comparing various GPS accuracy in position determination under various circumstances. Chamberlain (2002) tested the performance of some Trimble GeoXT global positioning system receivers. Wing et al., (2005) investigated the accuracy and reliability of consumer-grade GPS receivers under 
differing canopy conditions. The accuracy of six different GPS receivers was accessed under various canopies: open sky, young forest, and closed canopy. Jose et al., (2006) conducted a study which aimed at determining an appropriate method and receiver for position assessment under various forest canopy covers, in terms of easiness of use, accuracy, reliability, and the ratio accuracy/cost was also carried out in Vega de Espinareda municipality (El Bierzo Region), close to the University of León in Ponferrada (North East of Spain). In the study, recreational GPS receivers (GARMIN eTrex Euro, GARMIN 12XL, GARMIN Summit, GARMIN Geko 201) and more precise GPS receivers (Topcon Hiper+) were deployed at 17 forest locations which consisted of 3 measurements with each receiver per plot and positioning method. Tucek and Ligos (2002) also both performed a test of three GPS receivers of GIS category (Topcon Turbo G1, Topcon, Magellan ProMark X-CM, Magellan, March II-E, Corvalis Microtechnology) forest canopies. Kindra and Keith (2006) presented a paper comparing the precision and accuracy of five current Global Positioning System (GPS) receivers-Trimble ProXR, Trimble GeoXT without Wide Area Augmentation System (WAAS), Trimble GeoXT with the WAAS, Trimble GeoExplorer II, and an HP/Pharos receiver. They conducted a field study of 15 established survey markers in the City of Pocatello, Idaho. The observation was done on ten different dates with uniform settings e.g., averaging and acceptable Point Dilution of Precision (PDOP).

From the resources available online, it could be inferred that published studies comparing various GPS receivers are limited. Worthy of mention is the fact the no study has been conducted on the accuracy of South, Sokkia and ProMark GPS devices in obtaining geographic coordinates. Therefore a field study comparing these different GPS receivers to determine their optimum applicability for various uses is appropriate and relevant.

\section{MATERIALS AND METHODS}

Study area: The fieldwork was carried out on selected control points around the Staff Quarters, Oba-Nla, within the Federal University of Technology, Akure (FUTA) Campus. A map of the study area is as shown in figure 1

Survey stations used for the field study were selected based on their stability and accessibility. The Government control beacon located in front of the Survey department of the office of the SurveyorGeneral, Ondo state; was used as the base for the GPS observations. The pillar information as obtained from the Department of survey and mapping are presented Table 1.

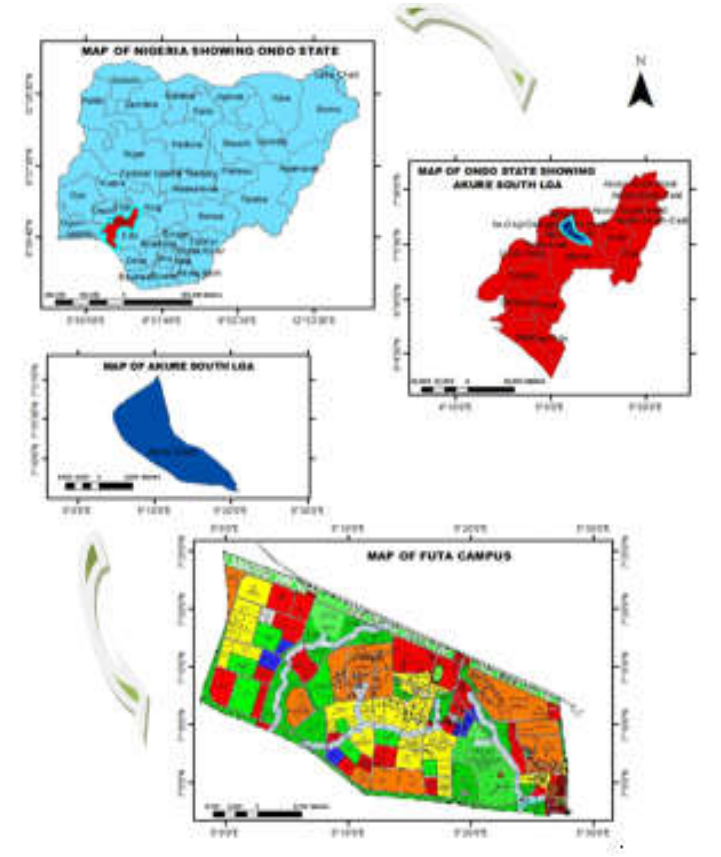

Fig 1: Map showing the study area

Reconnaissance and field survey planning: A schematic representation of the project procedure is presented in figure 2 .

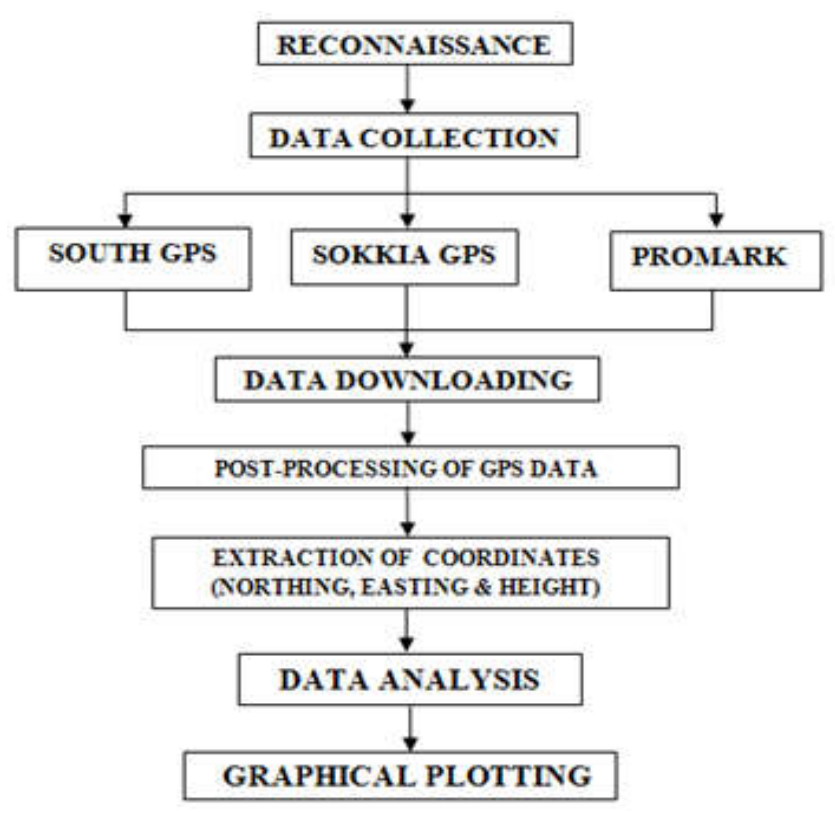

Fig 2: Framework for project procedures Source: Authors field work

Table 1: The pillar information as obtained from the Department of survey

\begin{tabular}{llll}
\hline Station ID & Northing $(\mathrm{m})$ & Easting $(\mathrm{m})$ & Height $(\mathrm{m})$ \\
\hline GA1S & 802854.974 & 740771.529 & 345.450 \\
\hline
\end{tabular}


To ensure that the field survey was timed at days and periods when PDOP was good, mission planning was carried out in this study. The mission planning for this study was run by Trimble GNSS planning online software that uses an almanac data file of the observation day. This software gave plots such as polar sky, GDOP, and Satellite Visibility for the days of observation. The basic considerations in choosing a survey point which included avoidance of obstructions above $15^{0}$ elevation angles, absence of reflecting surface or electrical installation to avoid signal disturbances were all observed before data acquisition. These criteria ensured the best operating condition for each GPS receiver, thereby eliminating as much environmental influence as possible in the field observation.

Data collection and processing: The GPS receivers used for this project are: South H66/H88, Sokkia radian IS and ProMark 3. They were tested before being deployed for the fieldwork and the batteries checked to ensure they are fully charged and that they had enough memory to store the data. All GPS observations took place on 3 different days. At each observation point, care was taken to record the data in the same way. South GPS receiver was first used, followed by Sokkia and finally ProMark. A Static method of GPS surveying was used in the field survey.

After the data has been collected with the 3 GPS receivers, the data was downloaded from the memory unit of the receivers into a computer system for onward processing. The next phase after data downloading is the processing of the data. Data processing for this project involves post-processing of the downloaded data from the 3 GPS receivers using the processing software package provided by the manufacturers. South GPS raw data was postprocessed using South GPS pro 4.0. Software, Sokkia GPS raw data was post-processed using Spectrum Survey 4.2 software, and ProMark GPS raw data was post-processed using Trimble precision GNSS solution 3.80 .8 software.

Data quality: Roe (2008) defined quality control as the efforts and procedures researchers put in place to ensure the quality and accuracy of data being obtained using the methodologies chosen for a particular study. To ensure the quality of the data acquired in this study, the GPS receivers were subjected to the best operating condition and the observation procedures were identical for all the five stations and days. Although GPS is an all-weather data collection platform, the weather conditions on collection dates were skies relatively cloud-free in all cases. Similarly, Data collection was executed on days when Dilution of Precision (DOP) is within acceptable limits as given by John et al., (2010) i.e. between 3-6.

\section{RESULTS AND DISCUSSION}

This section discusses how results from the fieldwork are analyzed and presented. Tables and graphs were used in presenting the various analysis carried out. Tables 1-3 are the Post Processed Northing, Easting and Height coordinates as obtained from the three GPS receivers.

Statistical investigations were carried out to test the reliability of the coordinates. The hypothesis was tested using One-way ANOVA at $95 \%$ confidence level.

- Null Hypothesis: $\mathrm{H}_{0}: \mu_{1}=\mu_{2}=\mu_{3}$. There is no significant difference between the Northing, Easting, and Height coordinates recorded by the three GPS receivers.

- Alternative hypothesis: $\mathrm{H}_{1}: \mu_{1} \neq \mu_{2} \neq \mu_{3}$. There is a significant difference between the Northing, Easting, and Height coordinates recorded by the three GPS receivers.

Result of the ANOVA tests for the Northing, Easting and Height coordinates are shown in Tables 4-6 respectively.

Table 1: Northing coordinates from the 3 GPS receivers

\begin{tabular}{llll}
\hline Stn & \multicolumn{3}{c}{ Northing $(\mathrm{mN})$} \\
\cline { 2 - 4 } & South & Sokkia & ProMark \\
\hline SV 13 & 808050.090 & 808049.998 & 808050.096 \\
\hline SV 14 & 808225.141 & 808225.013 & 808225.402 \\
\hline SV 15 & 808241.709 & 808241.057 & 808241.667 \\
\hline SV 16 & 808252.217 & 808251.972 & 808252.288 \\
\hline SV 17 & 808073.575 & 808073.433 & 808073.661 \\
\hline
\end{tabular}

Table 2: Easting coordinates from the 3 GPS receivers

\begin{tabular}{llll}
\hline Stn & \multicolumn{3}{l}{ Easting $(\mathrm{mE})$} \\
\cline { 2 - 4 } & South & Sokkia & ProMark \\
\hline SV 13 & 735059.559 & 735059.599 & 735059.607 \\
\hline SV 14 & 735070.882 & 735070.783 & 735071.160 \\
\hline SV 15 & 735327.261 & 735326.654 & 735327.116 \\
\hline SV 16 & 735536.468 & 735536.442 & 735536.539 \\
\hline SV 17 & 735557.723 & 735557.455 & 735557.541 \\
\hline
\end{tabular}

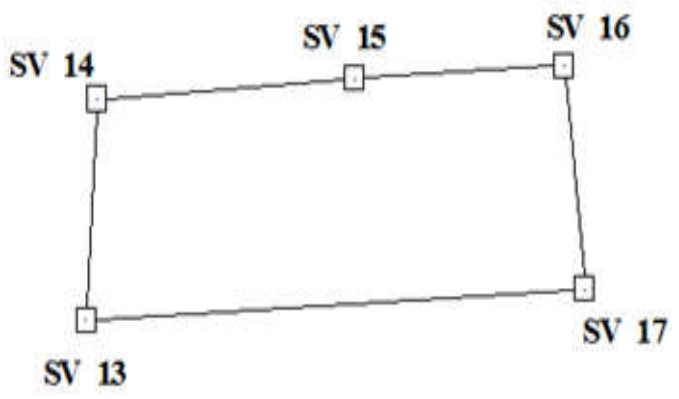

Fig 3: AutoCAD plot of Northing and Easting coordinates from the 3 GPS receivers 
Table 3: Height coordinates from the 3 GPS receivers

\begin{tabular}{llll}
\hline Stn & \multicolumn{3}{c}{ Height $(\mathrm{m})$} \\
\cline { 2 - 4 } & South & Sokkia & ProMark \\
\hline SV 13 & 379.480 & 378.480 & 378.540 \\
\hline SV 14 & 375.347 & 374.642 & 374.601 \\
\hline SV 15 & 381.645 & 381.988 & 380.867 \\
\hline SV 16 & 386.362 & 385.800 & 385.056 \\
\hline SV 17 & 388.958 & 388.200 & 388.007 \\
\hline
\end{tabular}

Table 4: One-way ANOVA for Northing coordinates

\begin{tabular}{|c|c|c|c|c|c|}
\hline & Sum of Squares & df & Mean Square & $\mathrm{F}$ & Sig. \\
\hline Between Groups & 0.295 & 2 & 0.148 & 0.000 & 1.000 \\
\hline Within Groups & 115739.685 & 12 & 9644.974 & & \\
\hline Total & 115739.981 & 14 & & & \\
\hline \multicolumn{6}{|c|}{ Table 5: One-way ANOVA for Easting coordinates } \\
\hline & Sum of Squares & df & Mean Square & $\mathrm{F}$ & Sig. \\
\hline Between Groups & 0.132 & 2 & 0.066 & 0.000 & 1.000 \\
\hline Within Groups & 698192.232 & 12 & 58182.686 & & \\
\hline Total & 698192.364 & 14 & & & \\
\hline
\end{tabular}

Table 6: One-way ANOVA for Height coordinates

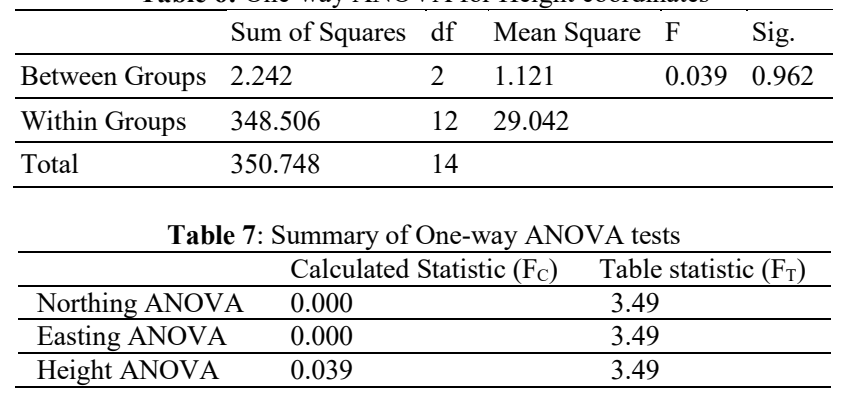

The almost exact agreement among the Northing and Easting coordinates as Shown in Tables 1 and 2 indicate the level of precision of the three GPS receivers. The AutoCAD plot in Figure 3 of the Northing and Easting coordinates shows an overlap of the observations from the three GPS receivers which also indicate their level of precision. However, obvious variation can be observed from the height coordinates obtained by the three GPS receivers as seen in Table 3.

From the One-way ANOVA test for the Northing coordinates, the calculated statistic, $\mathrm{F}_{\mathrm{C}}=0.000$ and the table statistic, $F_{T}=3.49$. For the Easting coordinates, the calculated statistic, $\mathrm{F}_{\mathrm{C}}=0.000$ and the table statistic, $\mathrm{F}_{\mathrm{T}}=3.49$. For the Height coordinates, the calculated statistic, $\mathrm{F}_{\mathrm{C}}=0.039$ and the table statistic, $\mathrm{F}_{\mathrm{T}}=3.49$. Based on the result of these tests, since $\mathrm{F}_{\mathrm{C}}<$ $\mathrm{F}_{\mathrm{T}}$ for the Northing, Easting and Height Coordinates, it, therefore, suggests that the null hypothesis $\left(\mathrm{H}_{0}\right)$ that there is no significant difference between the coordinates is accepted. The conclusion, therefore, is that there is no statistically significant difference between the coordinates obtained by the three GPS receivers at $95 \%$ confidence level.

Misclosure analysis: According to Valbuena et al., (2010), the analysis of the horizontal component of absolute error is confirmed to be a better descriptor of the performance of GNSS receivers. Therefore to evaluate the accuracy of the coordinates obtained using the receivers; horizontal, vertical and 3dimension accuracies were calculated using equations (i), (ii), and (iii) respectively.

$$
\begin{aligned}
& S_{H}=\sqrt{\left(N_{i}-N\right)^{2}+\left(E_{i}-E\right)^{2}} \\
& S_{V}=\sqrt{\left(Z_{i}-Z\right)^{2}} \\
& S_{P}=\sqrt{\left(N_{i}-N\right)^{2}+\left(E_{i}-E\right)^{2}+\left(N_{i}-N\right)^{2}}
\end{aligned}
$$

Where: $\mathrm{S}_{\mathrm{H}}=$ Horizontal accuracy; $\mathrm{S}_{\mathrm{V}}=$ Vertical accuracy; $\mathrm{S}_{\mathrm{P}}=3-\mathrm{D}$ accuracy; $\mathrm{N}=$ True Northing; $\mathrm{E}=$ True Easting; $\mathrm{Z}=$ True Height; $\mathrm{N}_{\mathrm{i}}=$ Observed Northing; $\mathrm{E}_{\mathrm{i}}=$ Observed Easting; $\mathrm{Z}_{\mathrm{i}}=$ Observed Height 
Measuring GPS accuracy requires some indication of "truth" or known reference. The mean of the coordinates was used as the "True" (most probable) value.

The calculated Horizontal, Vertical and 3-D position misclosures for the three GPS receivers are presented in Tables 8, 9, and 10 respectively.

\begin{tabular}{|c|c|c|c|}
\hline \multirow[t]{2}{*}{ Stn } & \multicolumn{3}{|c|}{ Horizontal misclosure } \\
\hline & $\begin{array}{l}\text { South } \\
\text { (m) }\end{array}$ & $\begin{array}{l}\text { Sokkia } \\
(\mathrm{m})\end{array}$ & $\begin{array}{l}\text { ProMark } \\
\text { (m) }\end{array}$ \\
\hline SV 13 & 0.0412 & 0.0643 & 0.0393 \\
\hline SV 14 & 0.0743 & 0.2343 & 0.3075 \\
\hline SV 15 & 0.3413 & 0.5514 & 0.2167 \\
\hline SV 16 & 0.0604 & 0.1918 & 0.1403 \\
\hline SV 17 & 0.1512 & 0.1708 & 0.1093 \\
\hline Average & 0.1337 & 0.2425 & 0.1626 \\
\hline
\end{tabular}

Table 9: Comparison of Vertical misclosure

\begin{tabular}{llll}
\hline \multirow{2}{*}{ Stn } & \multicolumn{3}{c}{ Vertical misclosure } \\
\cline { 2 - 4 } SV 13 & South(m) & Sokkia(m) & ProMark(m) \\
\hline SV 14 & 0.2337 & 0.1249 & 0.0861 \\
\hline SV 15 & 0.0210 & 0.0489 & 0.0687 \\
\hline SV 16 & 0.3879 & 0.0037 & 0.4006 \\
\hline SV 17 & 0.3246 & 0.0355 & 0.4670 \\
\hline Average & 0.2771 & 0.0902 & 0.2336 \\
\hline
\end{tabular}

Table 10: Comparison of 3-D position misclosure

\begin{tabular}{lccc}
\hline Stn & \multicolumn{3}{c}{ Position (3-D) misclosure } \\
\cline { 2 - 4 } & $\begin{array}{c}\text { South } \\
(\mathrm{m})\end{array}$ & $\begin{array}{c}\text { Sokkia } \\
(\mathrm{m})\end{array}$ & $\begin{array}{c}\text { ProMark } \\
(\mathrm{m})\end{array}$ \\
\hline SV 13 & 0.4594 & 0.1892 & 0.1254 \\
\hline SV 14 & 0.3080 & 0.2832 & 0.3762 \\
\hline SV 15 & 0.3623 & 0.7896 & 0.6173 \\
\hline SV 16 & 0.4483 & 0.1955 & 0.6073 \\
\hline SV 17 & 0.4758 & 0.2063 & 0.2548 \\
\hline Average & 0.4108 & 0.3328 & 0.3962 \\
\hline
\end{tabular}

Table 11: Summary of calculated average misclosures

\begin{tabular}{|c|c|c|c|}
\hline \multirow{3}{*}{$\begin{array}{l}\text { GPS } \\
\text { Receivers }\end{array}$} & Average & Average & Average \\
\hline & Horizontal & Vertical & $3-\mathrm{D}$ \\
\hline & Misclosure & Misclosure & $\begin{array}{l}\text { Position } \\
\text { Misclosure }\end{array}$ \\
\hline South & 0.1337 & 0.2771 & 0.4108 \\
\hline Sokkia & 0.2425 & 0.0902 & 0.3328 \\
\hline ProMark & 0.1626 & 0.2336 & 0.3962 \\
\hline
\end{tabular}

Results from the comparison of the average horizontal misclosure show that South GPS had the lowest value of 0.1337 , followed by ProMark GPS, 0.1625 ; while Sokkia had the highest value of 0.2425 ; this indicates that South GPS receiver was best in obtaining geographic information in the horizontal position. In the same vein, a comparison of the average vertical misclosure shows that Sokkia GPS had the lowest value of 0.0902; ProMark GPS, 0.2336, while South GPS had the highest value of 0.2771 ; thereby implying that Sokkia GPS receiver was best in obtaining geographic information in the Vertical position.
Meanwhile, the average 3-D position misclosure indicates that Sokkia has the least value of 0.3328 , as ProMark GPS had 0.3962, while South GPS had the highest value of 0.4108; showing that Sokkia performed best in the 3-Dimensional position.

Conclusion: This study evaluated the accuracy of coordinates of selected points obtained from three GPS receivers using appropriate statistics. The result clarifies that any of the GPS receivers can provide reasonable accurate data in terms of horizontal and vertical positions. The study further shows that the selection of the optimal GPS receiver in this study will largely be determined by the user's needs and the project's specifications. However, further work would be recommended on the significant difference in Heights obtained from the GPS receivers used in this study.

\section{REFERENCES}

Chamberlain, K; McCullough, M (2002). Performance Testing of the TrimbleGeoXT Global Positioning System Receiver. In: Draft Report Global Positioning System, United States Department of Agriculture service. Accessed via http://www.fs.fed.us/database/gps/mtdc/geo_xt/ trimble_geoxt.pdf.

John, D; James, B; Robert, B; McMaster; Chris R (2010).Manual of geospatial science and technology, $2^{\text {nd }}$ edition pp.204CRC press.

Jose,R; Flor, A; Enoc, S; Antonio, G(2006). Comparison of GPS Receiver Accuracy and Precision in Forest Environments: Practical Recommendations Regarding Methods and Receiver Selection. In: XXIII FIG Congress Munich paper, Germany.

Sjoberg, LE (2012). Solutions to the ellipsoidal Clairaut constant and the inverse geodetic problem by numerical Integration. Journal of Geodetic Sci. 3(2). 110-110.

Tucek, J; Ligos, J (2002). Forest canopy influence on the precision of location with GPS receivers. Journal of forest science, 48, (9): 399-407

Kindra, S; Keith, W (2006). Comparing GPS Receivers: A Field Study. Accessed via http://giscenter.isu.edu/research/projects/compa ringgps_urisavol18no2.pdf

Valbuena, R; Mauro, F; Rodriguez-Solano, R; Manzanera, J (2010). Accuracy and precision of GPS receivers under forest canopies in a 
mountainous environment. Spanish Journal of Agricultural Res. 8(4), 1047-1057.

Roe, D (2008): Quality control. Encyclopedia of survey research methods. In P. Lavrakas (Ed.), Thousand Oaks, CA: SAGE Publications, Inc.; pp. 650-652.
Shannon, K; Ellis, C; Hoette, G (2002). Performance of "low-cost" GPS receivers for yield mapping. In: ASAE Paper No.021151.

Wing, MG; Eklund, A; Kellogg, L (2005). Consumer Grade Global Positioning System (GPS) Accuracy and Reliability. Journal of Forestry, 103(4), 169-173. 